\title{
The hydrophobicity modulation of glass and marble materials by different Si-based coatings
}

\author{
Eleonora Pargoletti ${ }^{\text {a, b}}$, Lavinia Motta ${ }^{\text {a }}$, Valeria Comite ${ }^{\mathrm{a}, \mathrm{b}}$, Paola Fermo ${ }^{\mathrm{a}, \mathrm{b}}$, Giuseppe Cappelletti ${ }^{\mathrm{a}, \mathrm{b}}{ }^{*}$ \\ ${ }^{a}$ Università degli Studi di Milano, Dipartimento di Chimica, via Golgi 19, 20133, Milano, Italy \\ b Consorzio Interuniversitario Nazionale per la Scienza e Tecnologia dei Materiali (INSTM), via Giusti 9, 50121, Firenze, Italy
}

\section{A R T I C L E IN F O}

\section{Keywords:}

Glass

Marble

Hydrophobic Si-based coatings

Water capillary absorption

Vapor permeability

Ageing test

\begin{abstract}
A B S T R A C T
Hydrophobic polymers applied on hydroxylated surfaces increase their durability against undesired weathering processes. The achievement of a certain degree of surface hydrophobicity (reducing the water permeation) constitutes one of the main research focuses. Herein, two commercial Si-based resins (e.g. Alpha ${ }^{\circledR}$ SI30 and Bluesil®BP9710), directly applied on both glass and Carrara marble substrates, and a silanization process by using trichloromethylsilane (TCMS) were adopted. Contact angle measurements together with hysteresis determination and Surface Free Energy (SFE) were carried out to evaluate the hydrophobic features. Hence, since only in the case of TCMS a good hydrophobicity was achieved $\left(\theta\right.$ around $\left.150^{\circ}\right)$, two commercial polysiloxane-based additives (e.g. TegoPhobe $1500 \mathrm{~N}$ and TegoPhobe 1650 ) were added respectively to Alpha ${ } \mathrm{SI} 30$ and Bluesil@BP9710, according to their chemical compatibility. These auxiliary substances allowed to decrease the wettability features of either glass or marble. Furthermore, since all the investigated coatings could be used as stone materials protective agents, water capillary absorption and vapor permeability tests were performed. Also in this case, TCMS revealed to be the most performing one among the adopted silane-based resins, thanks to the drastic reduction of absorbed water and the decrease of vapor permeability within the threshold value of $50 \%$. Finally, the coatings stability was evaluated by accelerated ageing tests.
\end{abstract}

\section{Introduction}

Over the past decades, the achievement of surface hydrophobicity has been one of the main challenging issues to deal with by the contemporary scientists [1-4]. In particular, it is widely reported that hydrophobic surfaces can be obtained by both their modification using low-surface-energy coatings and by increasing the relative surface area (e.g. introducing surface roughness) [5].

Among the numerous research fields in which the hydrophobicity is very desirable, the protection of monuments of the Cultural Heritage deserves attention [6-10]. Indeed, both natural and artificial stone materials suffer from salts [11,12] and biological [13-15] attacks that can lead to their rapid degradation. The main cause is the presence of water, due to rain and humidity, which vehiculates salts and bacteria inside the stones, thus provoking either their break or the molds growth. In order to block these degradative processes, a highly hydrophobic protective coating must be applied on the surface of the stone $[2,12]$.
Furthermore, an ideal resin has to be not only a good water repellent agent, but it should also guarantee transparency, durability over time, easiness to remove and resistance both to UV and bacterial attacks [16-19]. Hence, quite a few polymers have been already investigated, such as acrylic [20-22], alkyl [23], silane and siloxane-based ones [24-28]. Among them, Si-based resins are particularly interesting thanks to the possibility of creating tailored coatings, by changing the chain length, molecular weight and functional groups. Tsakalof et al. [29] evaluated the performances of four synthetic coatings (siloxane-, siloxane/acrylic-, perfluoro ether- and fluoro-organosilane-based ones) for the protection of petrologically different stone substrates, such as marble, travertine, sandstone, etc. From water contact angles, water vapor permeability and water absorption by capillarity tests, they concluded that the most suitable coatings for all the investigated stone substrates seem to be the siloxane/acrylic copolymer and the polymethylsiloxane. Moreover, a fundamental requirement of any kind of hydrophobic polymer for stone protection is the chemical stability under ambient exposure. Eyssautier-Chuine et al. [2] studied the development of

\footnotetext{
* Corresponding author at: Università degli Studi di Milano, Dipartimento di Chimica, via Golgi 19, 20133, Milano, Italy.

Email addresses: eleonora.pargoletti@unimi.it (E. Pargoletti); lavinia.motta@studenti.unimi.it (L. Motta); valeria.comite@unimi.it (V. Comite); paola.fermo@unimi.it (P. Fermo); giuseppe.cappelletti@unimi.it (G. Cappelletti)
} 
eco-friendly coating with both hydrophobic and biocide properties, based on a silane/siloxane emulsion as a water repellent. The artificial ageing test revealed a moderate color variation on coated stones and, notwithstanding the simulation of rainfall caused the enlargement of pores and eroded the films in patches, the hydrophobic effect was preserved.

Moreover, glasses for architecture must have many functions in addition to their transparency. For example, hydrophobic modified-glasses with the functions of self-cleaning, UV reduction, anti-bacterial, energy conversion, and so on, will be used in buildings in the near future. Recently, reactive organo-silicon compounds have been exploited to modify the surface properties of inorganic materials, particularly for hydroxylated substrates such as silicon wafers and glass substrates [5,30,31]. Gao and McCarthy [32] obtained well-defined covalently attached monolayers by reacting alkylmethyldichlorosilanes and alkyltrichlorosilanes with silicon wafers in toluene, leading to superhydrophobic surfaces with both advancing and receding water contact angles approaching $180^{\circ}$. Furthermore, depending on reaction conditions (temperature, solvent and catalyst), chemistry of the organosilane (i.e. mono-, di- and tri-chlorosilanes together with their alkyl chain length), and surface texture, different structures (covalent attachment, self-assembly, vertical and horizontal polymerization) can be produced on the surface. Wong et al. [30] fabricated transparent superhydrophobic glass, by treating standard microscope slides with diluted methyltrichlorosilane in a simplified one-pot sol-gel process, at ambient conditions.

Therefore, herein a detailed study about the achievement of surface hydrophobicity of either glass or marble substrates has been investigated, by changing the kind of Si-based coatings. In our previous papers, two different commercial resins (i.e. Alpha ${ }^{\circledR S I 30}$ and Bluesil ${ }^{\circ} B P 9710$ ) have been deeply studied in terms of achieved hydrophobic degree, when applied on both glass and stone materials [33-35]. Moreover, a detailed investigation on the resins/hydroxylated substrate interactions was carried out in order to hypothesize the possible reaction mechanism [8]. Hence, starting from these recent results [8,33-35], herein an increase of the water repellency features of two different substrates, i.e. glass and marble (Carrara type), has been successfully achieved, by simply adding ad hoc siloxane-based compatible additives, that has led to a higher hydrophobic degree. Finally, an optimized silanization process has been performed on both the two materials by using trichloromethylsilane (TCMS) as the starting reagent, obtaining very promising and novel results. Actually, up to now, there are no available data about the use of this treatment on natural stone materials.

\section{Material and methods}

Two different substrates, i.e. glass and Carrara marble (commonly adopted in artifacts of Cultural Heritage), were used. For the former, pieces of standard microscope glass slide $(40 \mathrm{~mm} \times 40 \mathrm{~mm} \times 1 \mathrm{~mm})$ were pretreated by immersion in Piranha solution (3:1 mixture of concentrated $\mathrm{H}_{2} \mathrm{SO}_{4}$ and $30 \%$ wt $\mathrm{H}_{2} \mathrm{O}_{2}$ ) at $90^{\circ} \mathrm{C}$ for $1 \mathrm{~h}$ to remove all the impurities present on the surface. Subsequently, glass pieces were sonicated in MilliQ water for $10 \mathrm{~min}$ and dried in a vacuum oven at fixed pressure and temperature $\left(40 \mathrm{mbar}\right.$ and $40^{\circ} \mathrm{C}$, respectively) for $1 \mathrm{~h}$. Warning: piranha solution reacts strongly with organic compounds and should be handled with extreme caution.

In the case of the natural stone, small blocks (about $1 \mathrm{~cm} \times 1 \mathrm{~cm} \times 1 \mathrm{~cm}$ or $5 \mathrm{~cm} \times 5 \mathrm{~cm} \times 1 \mathrm{~cm}$ ) were polished with commercial grade diamond abrasive disks before any hydrophobizing treatment [34]. After the polishing procedure, they were rinsed in dis- tilled water to remove any impurities and dried in oven at $60^{\circ} \mathrm{C}$ for $24 \mathrm{~h}$. The substrates were labelled as $\mathrm{G}$ and $\mathrm{C}$ for glass and Carrara marble, respectively.

All the used chemicals were of reagent-grade purity and were used without further purification.

\subsection{Hydrophobic commercial coatings and water repellent additives}

Two commercially available resins were used to modify the wettability features of the bare substrates. The silicon-based solvent-borne resin Alpha ${ }^{\circledR}$ SI30 (purchased by Sikkens, labelled as Alpha) has been already widely characterized in our previous works $[8,34]$. It is composed by a mixture of a trimethoxysilane, with a quite long chain (i.e. iso-octyl) and a polydimethylsiloxane (PDMS). The present resin was applied as it is without any further dilution. Alpha ${ }^{\circledR S I 30}$ could give reticulation thanks to the presence of $-\mathrm{OCH}_{3}$ groups whose oxygen can act as a bridge between two Si atoms. Whereas, Bluesil®BP9710 (by Bluestar Silicones, labelled as Bluesil) is a concentrated Oil-in-Water emulsion (phase volume, $\varphi=0.44$ ) with an alkylpolysiloxane oligomer base and it is stabilized by exploiting a non-ionic emulsifier at alkaline $\mathrm{pH}$ (around 10). It was applied after a $1: 11$ dilution in water [33].

In order to enhance the hydrophobicity features given by the two commercial resins, two additives by Evonik Industries AG (TegoPhobe $1500 \mathrm{~N}$ and TegoPhobe 1650) were added as received in a relatively low amount (5\%wt with respect to the quantity of the commercial resins). In accordance to their chemical compatibility and solubility, TegoPhobe $1500 \mathrm{~N}$ (an amino functional polysiloxane in ether/isoparaffin solvent) was added to Alpha ${ }^{\circledR S I 30}$ (samples called as Alpha $+1500 \mathrm{~N}$ ). Instead, TegoPhobe 1650 (an emulsion of a modified polysiloxane resin in water-based medium) was combined to Bluesil®BP9710 (samples labelled as Bluesil +1650$)$. Indeed, both these two additives are reported to guarantee either excellent water-repellency or good resistance to rain.

The application of all the investigated coatings on glass or marble surfaces was carried out by using an air-brush system (Asturo airbrush, $700 \mu \mathrm{m}$ nozzle). The quantity of sprayed coatings was kept constant by controlling both spray pressure (2.5 bar) and the application time ( $3 \mathrm{~s}$ ). All the samples were dried for $24 \mathrm{~h}$ in an oven at constant temperature $\left(50^{\circ} \mathrm{C}\right)$.

\subsection{Trichloromethylsilane-based coating}

Silanization by trichloromethylsilane (TCMS) on glass substrates have been widely reported in the literature $[5,27,30]$. This procedure is mainly based on the adoption of toluene as the reaction solvent and only Zhang et al. have deeply investigated the role of the solvent in modifying the final hydrophobic features [36]. Furthermore, up to now, no studies concerning the present synthetic process on marble surfaces are available. Hence, herein, an optimized silanization procedure (in terms of reaction solvent, TCMS concentration and reaction duration) is reported, for both glass and Carrara materials.

Substrates silanization was carried out in closed glass vials by covering the surface with a suitable amount of cyclohexane (ACS Reagent grade, Sigma-Aldrich), instead of toluene. Indeed, the former can guarantee the same hydrophobic performances of the latter, but being less toxic [36]. Then, the correct volume of pure TCMS (99\%, purchased from Sigma-Aldrich) was added by using a micropipette in order to have a final concentration of TCMS equal to $0.08 \mathrm{M}$ or $0.12 \mathrm{M}$ for glass and marble, respectively. The reaction was performed at room temperature, for $60 \mathrm{~min}$ in the case of glass and $90 \mathrm{~min}$ for Carrara samples. Subsequently, the substrates were rinsed with cyclohexane, ethanol, ethanol:water (1:1) and water (10 mL for each step). The samples were 
then dried in oven at $60^{\circ} \mathrm{C}$ for $1 \mathrm{~h}$, in order to remove any solvent traces.

\subsection{Samples characterization}

Water Contact Angle (WCA) measurements on bare and coated substrates were performed using a Krüss Easy instrument. A drop of $7 \mu \mathrm{L}$ was gently placed on the surface; the drop profile was extrapolated using appropriate fitting functions (Circle and Tangent fitting methods) depending on the drop shapes. Measurements were repeated several times $(>20)$ to obtain a statistical population.

Dynamic contact angle (advancing and receding) measurements were performed to calculate the hysteresis value $\left(\theta_{\mathrm{i}}\right)$ [37].

Surface Free Energy (SFE) and the relative polar $\left(\gamma^{p}\right)$ and disperse $(\gamma$ $\left.{ }^{d}\right)$ components were evaluated by using the Owens-Wendt-Rabel-Kaelble (OWRK) method $[38,39]$ by using different high purity solvents (i.e. diiodomethane, diethylene glycol, ethylene glycol, ethylene glycol:water $=50: 50 \mathrm{v} / \mathrm{v}$ and water). Wetting Envelopes (WEs) were elaborated starting from the previous data, as reported in our previous work [39].

Capillary water absorption measurements were performed on both bare and coated materials following the standard protocol UNI EN 15,801 "Conservation of cultural property-test methods-determination of water absorption by capillarity" $[33,40,41]$. The total amount of water absorbed $\left(\mathrm{Q}_{\mathrm{tf}}\right)$ and the Capillary Absorption (CA) coefficient were determined, accordingly.

The Water Vapor Permeability (WVP) tests were performed by means of a methodology described in the European Standard Norma EN $15,803[33,42,43]$ and the Reduction of Vapor Permeability (RPV) were evaluated.

In order to verify the color modification of the coatings, after both their deposition and the ageing test (see in the following), transmittance spectra and colorimetric measurements were carried out, for glass and marble respectively. Transmittance analysis was performed between 300 and $800 \mathrm{~nm}$, by using a JASCO/UV-Vis/NIR spectrophotometer (model V-570 instrument). Instead, the chromatic coordinates were calculated according to the Commission Internationale d'Eclairage (CIELab method) [33,41], starting from diffuse reflectance spectra acquired in the UV-Vis spectral range from 800 to $350 \mathrm{~nm}$. According to the literature, no significant variation occurs when $\Delta E^{*}<3$ [44].

To evaluate both the homogeneity of the coated samples and the coatings thickness, the profile of the substrates surface was investigated by means of a contact profilometer (Bruker DektakXT), by repeating the measurements at least five times, on different areas of the same sample.

Scanning Electron Microscopy (SEM) analyses ware carried out both in Variable Pressure (VP) and Back-Scattering (BS) modes, by using Zeiss Evo 50EP (pressure of 50 Pa and accelerated electrons tension of $20 \mathrm{kV}$ ) equipped with an EDS Inca Energy 200 spectrophotometer.

\subsection{Ageing test}

Accelerated ageing test was performed to evaluate the stability of the hydrophobic coatings. Thus, samples were exposed to UV irradiations (500 W halide lamp, $215-365 \mathrm{~nm}$, irradiance specific power of $45.5 \mathrm{~mW}$ $\mathrm{cm}^{-2}$ ) for $50 \mathrm{~h}$. At the end of the test, the variations of both contact angle values and transmittance (for glass substrates) or $\Delta E^{*}$ parameter (for marble) were evaluated.

\section{Results and discussion}

\subsection{Enhancing the hydrophobicity by different Si-based coatings}

Apparent water contact angles along with the relative hysteresis values and the subsequent surface free energy calculation (the latter only in the case of glass substrates) were performed to evaluate the efficacy of the polymeric coatings in imposing the surfaces hydrophobicity. Fig. 1 well shows the increasing of the hydrophobic features for both the two studied materials. Indeed, from bare hydrophilic substrates $(\theta$ around $40-50^{\circ}$, droplet fitting profiles in Fig. S1a and b), an increase of water contact angle values was observed after the application of every tested coating. In detail, Bluesil resin seems to be the less performing one ( $\theta$ up to a value of around $90^{\circ}$ for marble and $65^{\circ}$ for glass), followed by Alpha (for which $\theta$ is around $115^{\circ}$ and $100^{\circ}$ in the case of marble and glass, respectively). Two interesting observations could be made: $i$ ) the coatings behavior strongly depends on the substrates material and, thus, on its surface characteristics (see the profilometry results in the following); ii) for either Bluesil or Alpha, the addition of polysiloxane-based additives effectively enhances the hydrophobic features (an increase from $\sim 15^{\circ}$ to $25^{\circ}$ for marble and $\sim 5^{\circ}$ for glass materials). Nevertheless, contact angle values higher than $130^{\circ}$ were not achieved in any case. Therefore, a silanization process, in which the polymeric resin (TCMS) was directly synthesized on the materials surfaces, was investigated. In this case, a high hydrophobic degree (reaching almost the superhydrophobic condition) was successfully obtained for both the two substrates ( $\theta$ equal to $149^{\circ}$ for marble and $140^{\circ}$ for glass, Fig. S1c and d). In the case of glass, the present results are fully in accordance with the ones reported in the previous literature. Yu et al. [30] reported that hydrophobic glass slides ( $\theta$ around $140^{\circ}$ ) could be obtained by means of diluted methyltrichlorosilane under similar experimental conditions $\left(\mathrm{T}=25^{\circ} \mathrm{C}\right.$, reaction time of $1 \mathrm{~h}$, final concentration of TCMS equal to $0.08 \mathrm{M})$. Seeger et al. [18,36] studied the solvent-controlled growth of Silane NanoFilaments (SNF) on the surface of glass slides, by simply regulating the type and ratio of solvents during hydrolysis and condensation of TCMS. High contact angles $\left(\theta>150^{\circ}\right)$ were achieved only by using toluene or its homologues, being ideal solvents for the growth of the SNFs. Moreover, Khoo et al. [45] followed the temporal development of the TMTS nano-architectures on glass surfaces (the chamber temperature and humidity

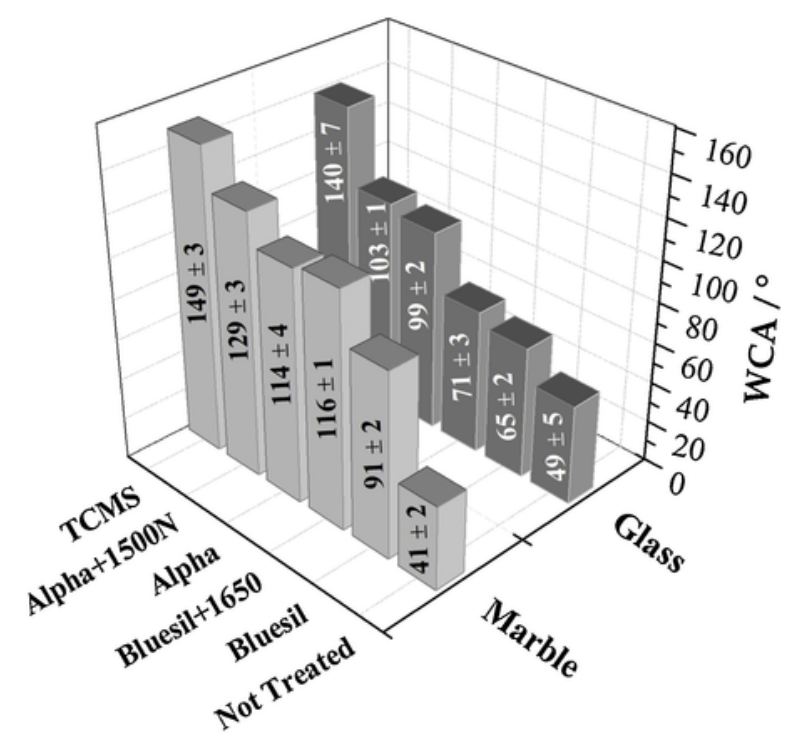

Fig. 1. Water contact angle (WCA) trend for both glass (dark grey) and Carrara marble (light grey) by varying the hydrophobic coating. 
remained constant at $21 \pm 1{ }^{\circ} \mathrm{C}$ and $60 \pm 1 \% \mathrm{RH}$, respectively; with a silane concentration of $0.014 \mathrm{M}$ ): the contact angle continued to increase from $120^{\circ}$ to $160^{\circ}$ after $30 \mathrm{~min}$ of reaction, remaining the same after $60 \mathrm{~min}$. On the contrary, to the authors' best knowledge, no similar data are reported in the case of marble substrates, representing the real novelty of the present work.

In order to explain the coatings hydrophobic behavior, the evaluation of the surface texture and the relative roughness characteristics is strictly required. Hence, SEM images have been acquired for Bluesil +1650 , Alpha $+1500 \mathrm{~N}$ and TCMS coated glasses (Fig. 2a, c and e). Both the two sprayed resins (e.g. Bluesil and Alpha) do not seem to homogeneously cover the substrate surfaces, since polymeric agglomerates can be observed (Fig. 2a and c). On the contrary, a well-defined and homogeneous coverage is typical of TCMS (Fig. 2e). Indeed, as reported by Fan-Gang et al. [45], trichloromethylsilane (at the same con- centration of the present work) can form interconnected 'ball-like' particles making discrete short fibers of a 3D quasi-network (clearly visible in the magnification shown in Fig. 2f). Furthermore, for all the protective coatings, the formation of resin/substrate bonds (schematic representations of Fig. 2b, d and g) takes place through the interaction between the hydrolysable substituents of silane and the hydroxyl groups of the substrates $[8,45]$. Thus, the very rough surface texture given by TCMS can guarantee high hydrophobic features, although characterized by an abrupt rise of the contact angle hysteresis $[45,46]$. To explain the latter phenomenon, a mixed wetting mode, in which a part of the apparent surface has transitioned to the Wenzel wetting mode whereas the remaining part is still Cassie-Baxter, has been proposed. Actually, rough surfaces show a different wetting behavior with respect to the ideal Young wettability, which comes from the combined effect between the surface chemistry and its texture [37]. Hence, two differ-

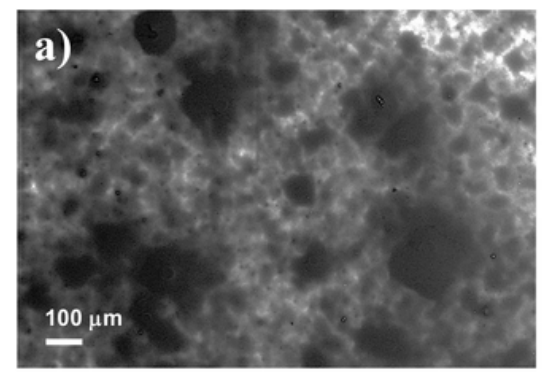

b)
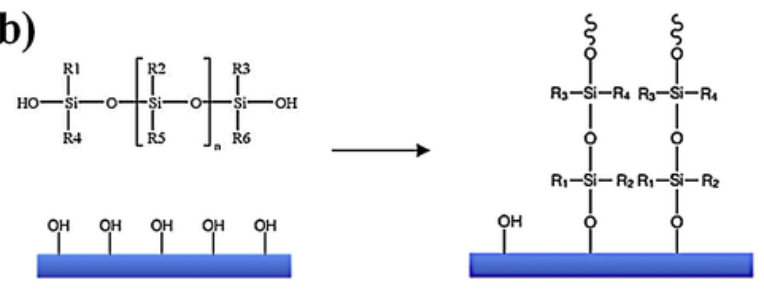

d)

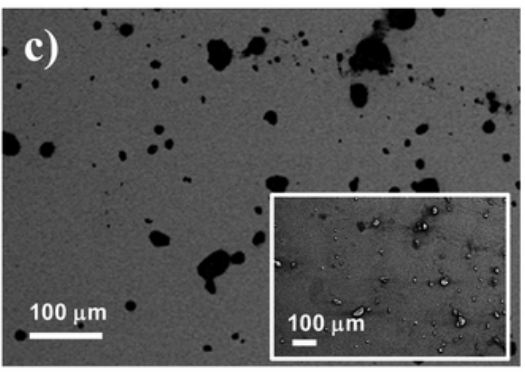

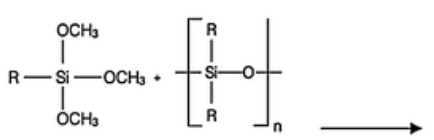
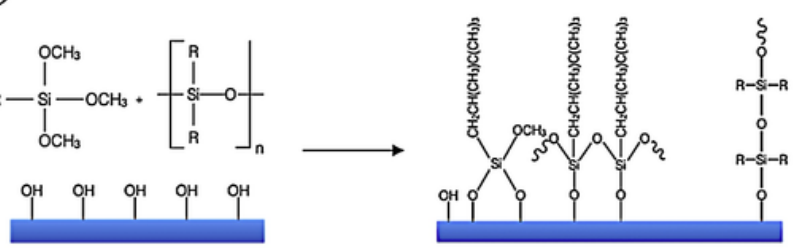

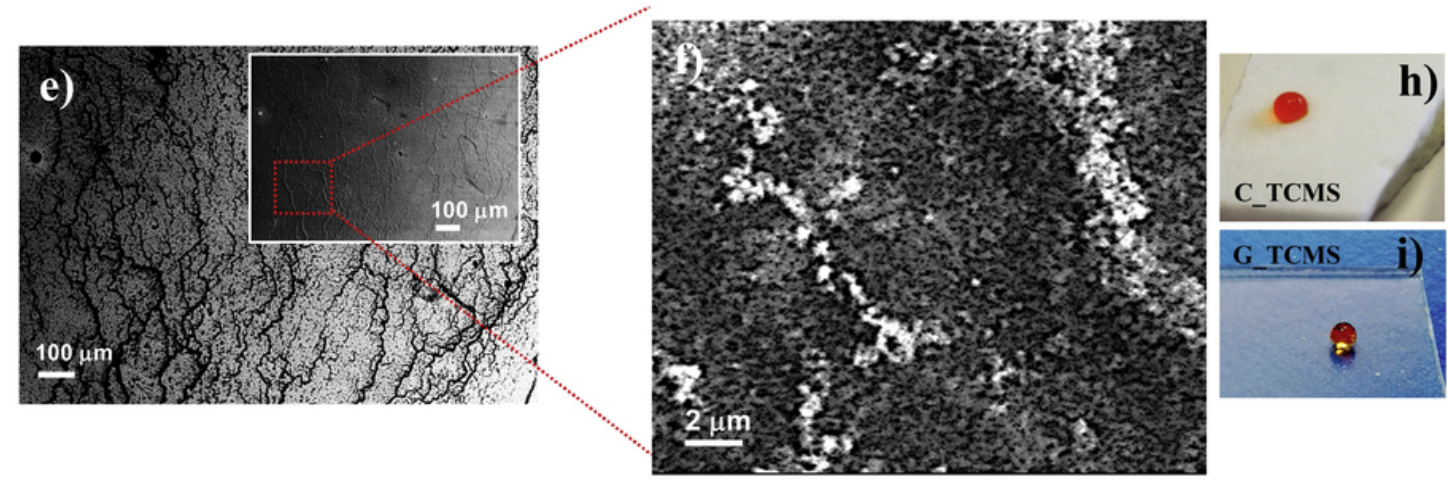

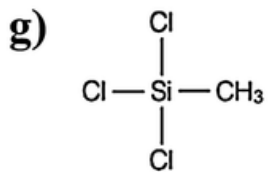
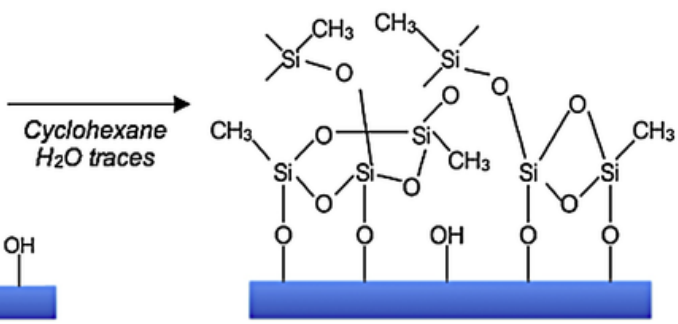

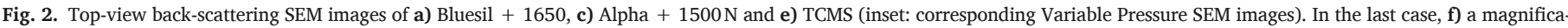

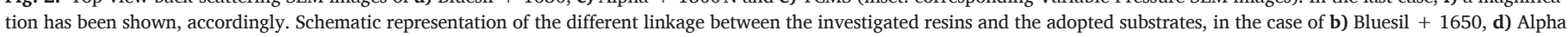
$+1500 \mathrm{~N}$ and g) TCMS. Photos of a water droplet on the surface of h) C_TCMS and i) G_TCMS, respectively. 
ent situations can occur: $i$ ) the liquid follows the actual surface profile (i.e. Wenzel model); ii) the liquid leaves air inside the texture, thus contacting the solid through the top of the asperities (i.e. Cassie-Baxter model). In the former case, the increase in the surface area provokes a rise in the material hydrophobicity and an increase in the corresponding hysteresis value; whereas, in the second situation, the hysteresis is very low, since the liquid has scarce interactions with the solid [37]. Another factor which contributes to the high contact angle hysteresis is

Table 1

Surface Free Energy (SFE), the relative polar $\left(\gamma^{p}\right)$ and disperse $\left(\gamma^{d}\right)$ components and hysteresis values $\left(\theta_{\mathrm{i}}\right)$ for all the investigated glass-coated samples. For G_TCMS the relative SFE could not be calculated due to the high surface hydrophobicity $\left(\theta_{\text {water }}>120^{\circ}\right)$.

\begin{tabular}{lllll}
\hline Sample & $\gamma^{p} / \mathrm{mN} \mathrm{m}^{-1}$ & $\gamma^{d} / \mathrm{mN} \mathrm{m}^{-1}$ & $\mathrm{SFE} / \mathrm{mN} \mathrm{m}^{-1}$ & $\theta_{\mathrm{i}} /{ }^{\circ}$ \\
\hline G & $24 \pm 5$ & $21 \pm 5$ & $45 \pm 10$ & - \\
G_Alpha & $2 \pm 1$ & $18 \pm 3$ & $20 \pm 4$ & 30 \\
G_Alpha + 1500 N & $<2$ & $16 \pm 2$ & $<18$ & 35 \\
G_Bluesil & $10 \pm 2$ & $24 \pm 4$ & $34 \pm 6$ & 33 \\
G_Bluesil + 1650 & $8 \pm 2$ & $20 \pm 3$ & $28 \pm 4$ & 40 \\
G_TCMS & - & - & - & 71 \\
\hline
\end{tabular}

the pinning effect caused by some hydrophilic defects. These defects can cause penetration of the water droplet between the surface asperities on a rough substrate, resulting in extremely high $\theta_{i}$ values $[45,46]$. In the present work, a corroboration of the growth of this fibrous network by either SEM images (Fig. 2f) and $\theta_{\mathrm{i}}$ values (i.e. around $70^{\circ}$; Table 1, 5th column) is reported. Conversely, as concerns Bluesil- and Alpha-based coatings, hysteresis values are smaller (about $30-40^{\circ}$; Table 1 ) as expected for substrates obeying the Wenzel wetting mode [37]. Thus, only in the case of TCMS a water droplet rolls away (for both glass and marble samples, Videos S1 and S2), confirming the superhydrophobicity of the polymeric layer (Fig. $2 \mathrm{~h}$ and i).

Moreover, profilometric measurements were also carried out in the case of bare and silane treated substrates: indeed, only Alpha $+1500 \mathrm{~N}$ and TCMS were studied due to the higher hydrophobicity degree (Fig. 1). As concern the glass material, the bare surface is almost flattened, with an average roughness (R) value of about $(5 \pm 1) \mathrm{nm}$ (Fig. 3a). The treatment with both the Alpha $+1500 \mathrm{~N}$ and TCMS has led to a slight increase of $\mathrm{R}$ (up to $(30 \pm 3)$ and $(50 \pm 2) \mathrm{nm}$, respectively). Instead, in the case of Carrara marble (Fig. 3b), the bare surface is much rougher $(\mathrm{R} \sim 800 \mathrm{~nm})$ than the glass one. The Alpha +
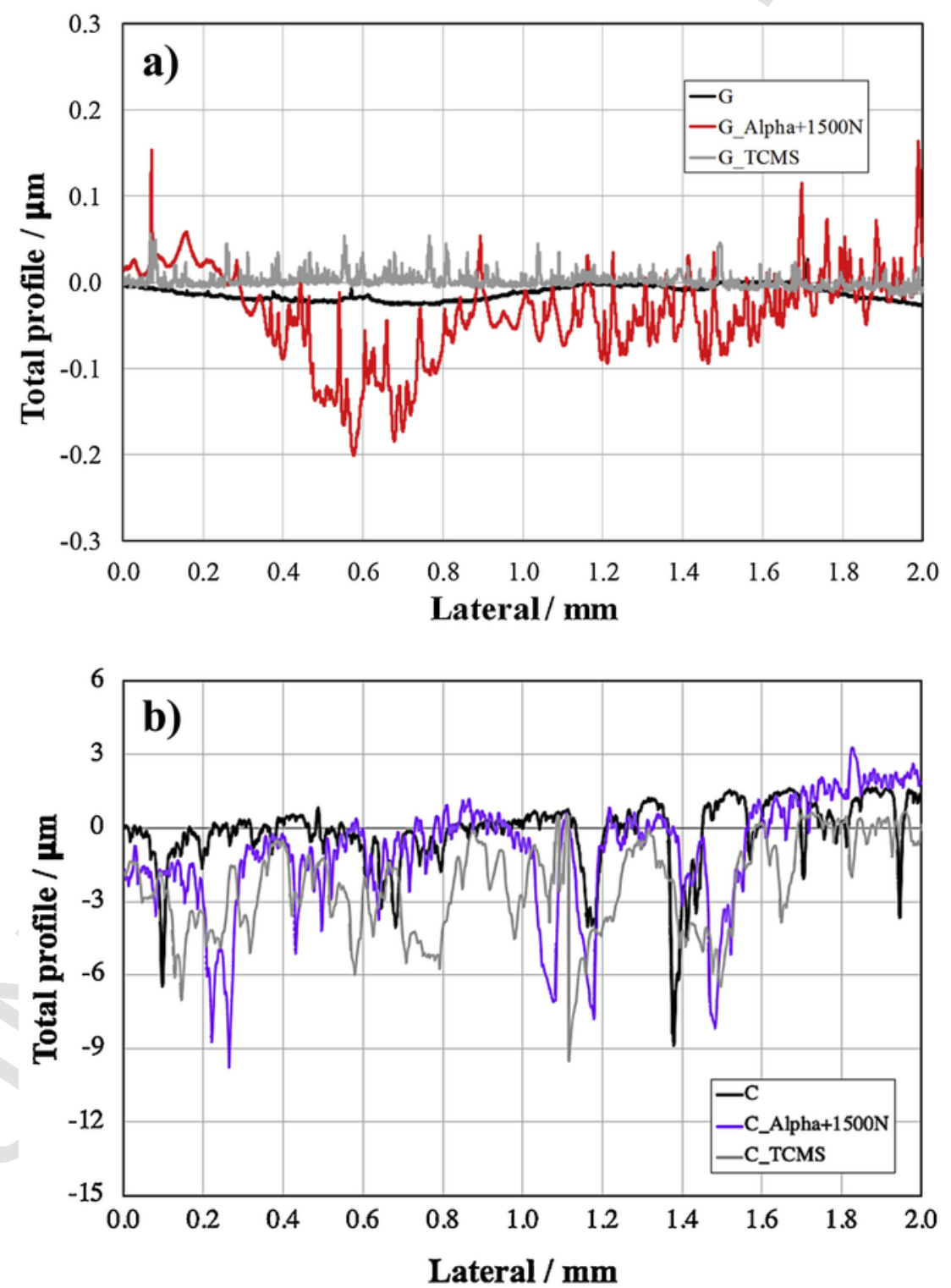

Fig. 3. Profilometry results for both bare and treated a) glass and b) Carrara substrates. 
$1500 \mathrm{~N}$ coating seems to preserve the roughness of the bare sample $\left(R^{\sim}\right.$ $700 \mathrm{~nm}$ ), whereas the TCMS one led to a slight increase of R, probably thanks to the formation of the nano-/micro-texture as previously mentioned ( $\mathrm{R}$ up to $2-3 \mu \mathrm{m}$ ) [36,47]. The coatings thicknesses have been also evaluated by profilometric measurements. Particularly, films have been scratched by using a metallic pin in the case of Alpha and Bluesil-based coatings and with a stylus, previously immersed in toluene, for TCMS films. Indeed, the latter is much more difficult to be mechanically removed. Hence, in the case of glass substrate, Alpha $+1500 \mathrm{~N}$ and Bluesil +1650 are around 400-500 nm thick (Fig. S2a); whereas TCMS forms a thinner film ( $\sim 10-20 \mathrm{~nm}$, Fig. S2b). On the contrary, on marble surface, Alpha $+1500 \mathrm{~N}$ and Bluesil +1650 coatings have a thickness of around $1 \mu \mathrm{m}$, which decreases for TCMS-treated marble ( $50-60 \mathrm{~nm})$.

After having evaluated both the surface characteristics and the relative wettability features, the Surface Free Energy measurements of the coated glass materials were determined along with the relative polar and disperse components (Table 1 and Fig. 4). No data were reported for bare and silane-clad marbles since the OWRK equation can be applied only for smooth surface and not for rough ones [38].

Fig. 4a shows the linear trends of the data relative to both bare and coated glass samples, corroborating the previous results concerning the contact angle values. Indeed, the decrease of the total surface energy values and particularly of the polar part (Table 1 and the slopes in Fig. 4) after the treatment confirms the hydrophobic features of the treated surfaces. In the case of C_TCMS, the OWRK method was not applicable because of the high surface hydrophobicity ( $\theta$ values higher than $120^{\circ}$ ). Once evaluated the SFE components, Wetting Envelopes (WEs) were drawn (Fig. 4b). Each curved profile points out the hydrophilic/ hydrophobic border (i.e. $\theta=90^{\circ}$ ) of the corresponding substrate. Thus, if water solvent (highlighted by a black dot in Fig. 4b) easily wets a surface $\left(\theta<90^{\circ}\right)$, its position in the graph lies in the area underlying the relative wetting envelope. Therefore, the previous results were corroborated as well, since for G_Alpha and G_Alpha $+1500 \mathrm{~N}$ the curves are much more flattened, so that the water dot remains outside the corresponding curves (i.e. contact angle higher than $90^{\circ}$ ).
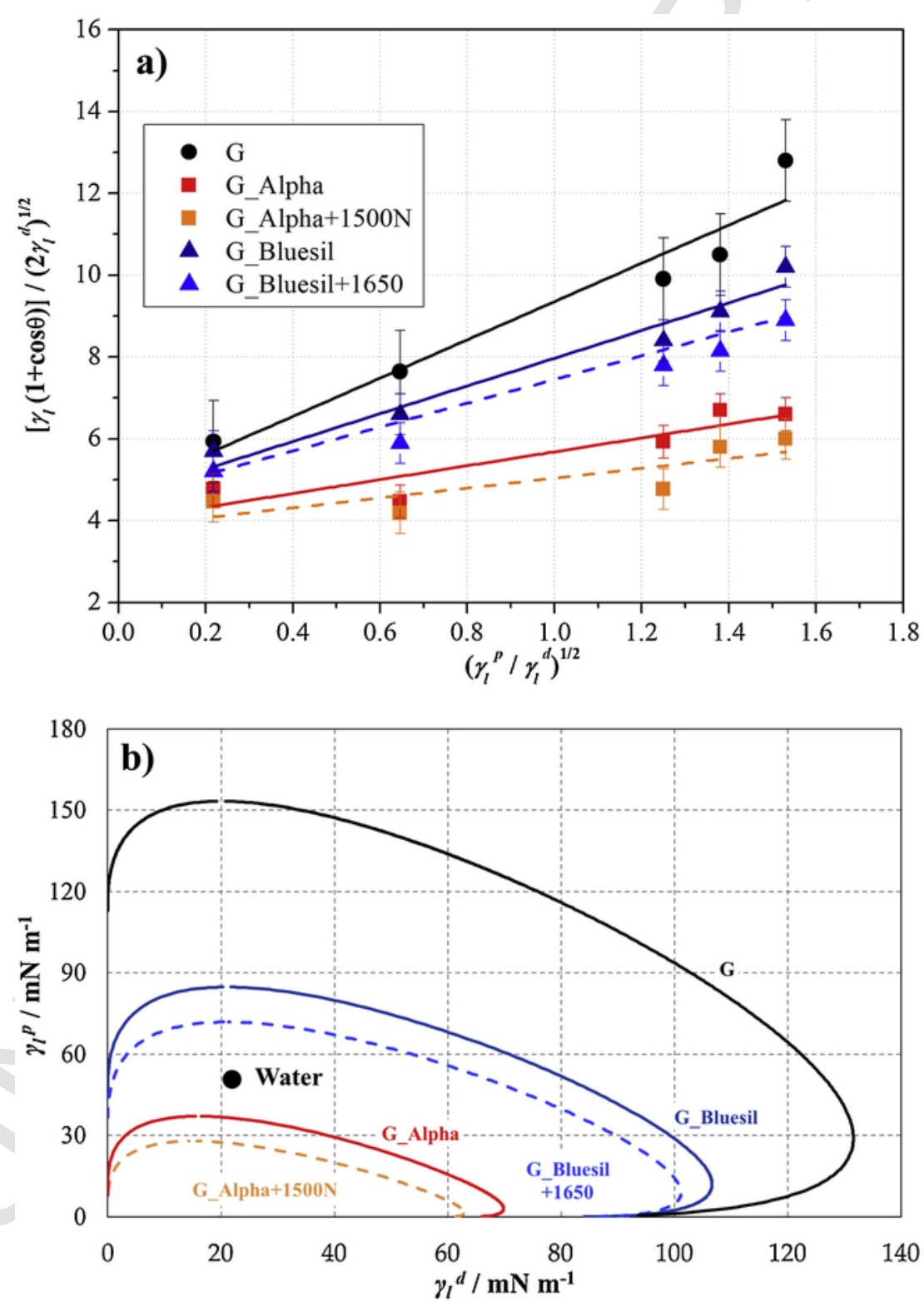

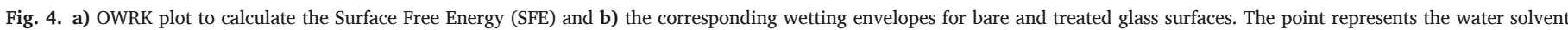
and each contour was drawn considering $\theta$ equal to $90^{\circ}$. 
Furthermore, all the coatings should guarantee the substrate color preservation. Hence, transmittance measurements for glass samples (Fig. S3a) and CIELab analysis (Table 2, 2nd column) for marble ones were performed. In both cases, all the protective coatings are invisible to naked eye (i.e. transmittance percentages between $92-94 \%$ in the range $400-800 \mathrm{~nm}$ and $\Delta E^{*}<3$ for all the substrates).

Table 2

Color variation $\left(\Delta E^{*}\right)$, water capillarity parameters (amount of water absorbed at final time, $\mathrm{Q}_{\mathrm{tf}}$ and water Capillary Absorption coefficient, CA) and Reduction of Vapor Permeability percentage (\%RPV) for Carrara marble.

\begin{tabular}{lllll}
\hline Sample & $\Delta E^{*}$ & $\mathrm{Q}_{\mathrm{tf}} / \mathrm{mg} \mathrm{cm}^{-2}$ & $\mathrm{CA} / \mathrm{mg} \mathrm{cm}^{-2} \mathrm{~s}^{-1 / 2}$ & $\% \mathrm{RVP}$ \\
\hline C & & 8.93 & 0.178 & - \\
C_Alpha & 1.5 & 5.57 & 0.016 & 9 \\
C_Alpha + 1500 N & 1.0 & 6.35 & 0.021 & 14 \\
C_Bluesil & 2.3 & 2.48 & 0.012 & 19 \\
C_Bluesil+1650 & 2.1 & 2.67 & 0.015 & 30 \\
C_TCMS & 2.2 & 2.76 & 0.017 & 48 \\
\hline
\end{tabular}

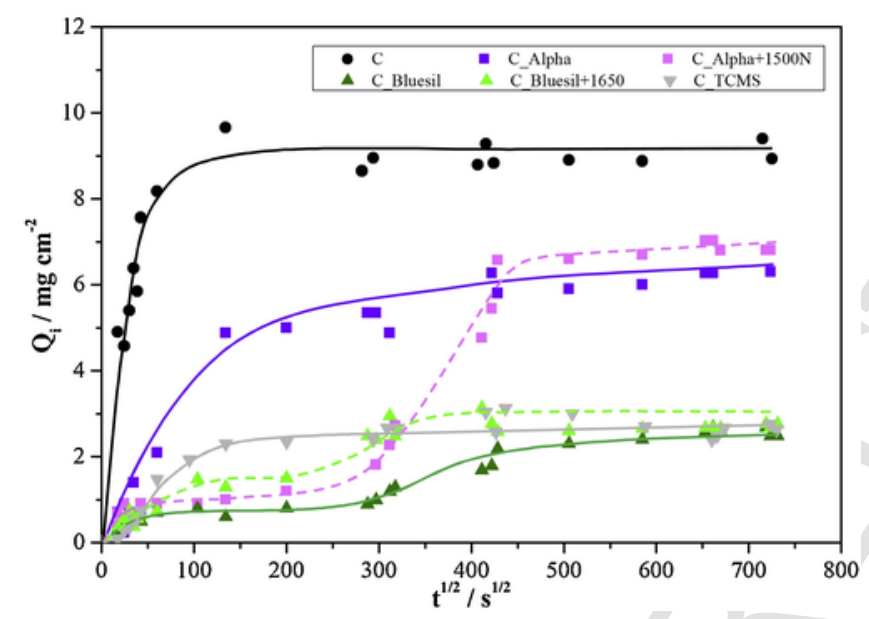

Fig. 5. Water capillary absorption curves for pure and coated Carrara marbles.

\subsection{Water capillary absorption and vapor permeability}

As concerns Carrara marble, an ideal hydrophobic and protective coating should hinder the water capillary absorption, whilst it should preserve vapor permeability to avoid the mold growth. Hence, either water capillary or vapor permeability tests were carried out.

Fig. 5 shows the amount of absorbed water per unit area $\left(Q_{i} / m g\right.$ $\mathrm{cm}^{-2}$ ) over time for both bare and Si-treated marble samples. For the untreated Carrara, high amount of water was absorbed $\left(\mathrm{Q}_{\mathrm{tf}}\right.$ equal to $8.93 \mathrm{mg} \mathrm{cm}^{-2}$; Table 2, 3rd column) especially at the beginning of the analysis (greater slope of the absorption curve, CA $=0.178 \mathrm{mg} \mathrm{cm}^{-2}$ $\mathrm{s}^{-1 / 2}$; Table 2, 4th column). When Alpha and Alpha $+1500 \mathrm{~N}$ resins were deposited, a slight decrease in the water absorbed amount occurred (Table 2, 3rd column and Fig. 5). On the contrary, for Bluesil, Bluesil +1650 and TCMS a dramatic reduction of $\mathrm{Q}_{\mathrm{tf}}$ was noticed. Moreover, for all the coatings a drastic decrease (of about one order of magnitude) of the CA parameter was registered, thus confirming their hydrophobic features.

Alongside a great reduction of water absorption by capillarity, the permeability of water vapor through the marble pores should be ensured [43]. Of course, as already reported, a silane- or silicone-based coating slightly decreases the stone transpiration [48]. However, as stated by Rodrigues and Grossi [49], the reduction of the vapor permeability can be considered negligible up to $50 \%$. Fig. 6 shows the cumulative mass change per unit area $(\Delta \mathrm{m})$ versus time for all the treated samples. Both Alpha-based resins have a good behavior in allowing the vapor flow $(\% \mathrm{RPV}<15 \%)$. On the contrary, a higher reduction of materials transpiration was observed for Bluesil and Bluesil +1650 (\%RPV $<30 \%$ ), and a more drastic decrease has been obtained for TCMS (Table 2, 5th column), caused by the compact and dense polymeric network.

Notwithstanding this fact, the vapor reduction is still within the accepted limit of 50\% [49].

\subsection{Si-based coating resistance to ageing test}

In order to evaluate the coatings stability, all the samples were treated under direct UV lamp irradiations for $50 \mathrm{~h}$, as an accelerated ageing test. For both glass and Carrara substrates, the possible hydrophobicity and color variations were determined. In Table 3 (2nd

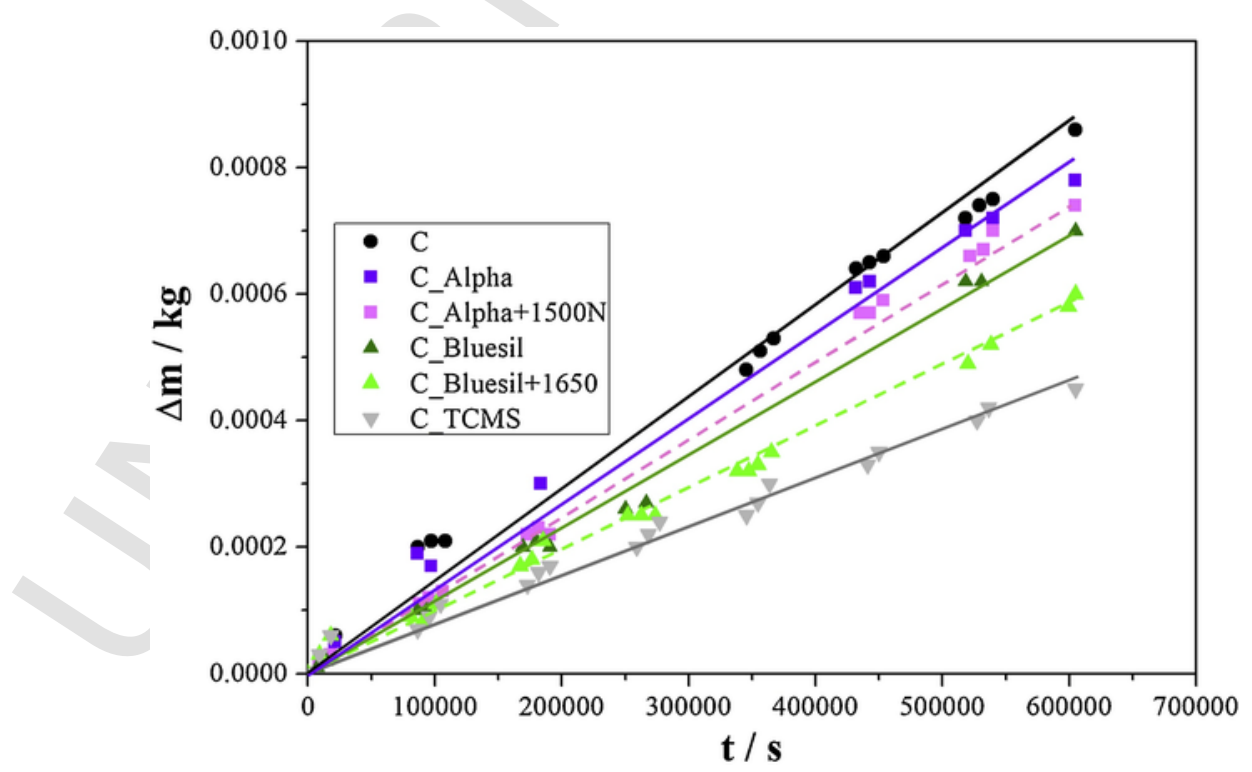

Fig. 6. Water vapor permeability curves for all the marble samples. 
Table 3

Contact angle and color variations after the ageing test ( $50 \mathrm{~h}$, under UV light).

\begin{tabular}{llll}
\hline Sample & Carrara & & Glass \\
\hline & $\Delta \theta /^{\circ}$ & $\Delta E^{*}$ & $\Delta \theta /^{\circ}$ \\
\hline Alpha & 17 & 0.7 & 2 \\
Alpha + 1500 N & 6 & 1.7 & 4 \\
Bluesil & -18 & 1.1 & 34 \\
Bluesil + 1650 & -2 & 0.6 & 19 \\
TCMS & 7 & 1.2 & -7 \\
\hline
\end{tabular}

and 4th columns), $\Delta \theta$ values have been reported. A good stability could be observed for Alpha-based resins (especially in the case of marble material, $\Delta \theta=+17^{\circ}$ and $+6^{\circ}$ for Alpha and Alpha $+1500 \mathrm{~N}$, respectively). On the contrary, by comparing Carrara and glass substrates a huge difference in the hydrophobicity preservation was seen for Bluesil-based coatings. Indeed, in the case of stone material the hydrophobic features were slightly lost $\left(\Delta \theta=-18^{\circ}\right.$ and $-2^{\circ}$ for Bluesil and Bluesil + 1650 , respectively); whereas, with coated-glass samples an increment of $\theta$ values was obtained $\left(\Delta \theta=+34^{\circ}\right.$ and $\left.+19^{\circ}\right)$, probably caused by the faster evaporation of water residues (Bluesil is an $\mathrm{O} / \mathrm{W}$ emulsion) inside the coatings due to the lower water/glass affinity with respect to the water/marble one. Moreover, the presence of the additives improves the resins stability for all the adopted substrates; nevertheless, also in this case, Alpha $+1500 \mathrm{~N}$ seems to be the most stable one either on glass or marble materials (Fig. S3c, d, f and g).

Finally, TCMS seems to preserve the starting hydrophobic behavior when applied on marble surface (Fig. S3h), but unfortunately it is not still so performing on glass material, after the ageing test (Fig. S3e). This is probably due to the concentration of the hydroxyl groups on the different surface substrates (higher in the case of marble species) that strongly determines the density of the polymerized nanostructures during the initial growth [45]. Hence, UV prolonged irradiation could remove the entrapped solvent molecules, thus provoking a partial rearrangement of the tridimensional network especially in the case of less compact film on glass. Actually, Zimmermann et al. [47] affirmed that a further annealing treatment significantly improves either coatings durability or hydrophobicity (an increase of $4-6^{\circ}$ of water contact angle). Then, the higher standard deviation of the WCA (e.g. $\pm 7^{\circ}$, Fig. 1) for this substrate corroborates the previous hypothesis.

Instead, as regard the possible color variation, neither for Carrara treated samples ( $\Delta E^{*}$ values; Table 3 , 3rd column) nor for glass ones (Fig. S3b), the substrates color modification is visible to naked-eye (see Fig. S3c-h).

\section{Conclusions}

Herein, a deep investigation on the hydrophobizing features of several commercial and in situ silane-based resins was made. Thinner films (around 20-60 nm) were obtained by direct growth of TCMS on the substrates surface, whereas much higher values (up to $1 \mu \mathrm{m}$ ) were reached by Alpha $+1500 \mathrm{~N}$ and Bluesil +1650 resin deposition via air-brush. Among the adopted hydrophobizing agents, the trichloromethylsilane (TCMS) coating gives the highest WCAs $\left(\theta>140^{\circ}\right)$ on both substrates, reaching almost the superhydrophobic conditions, due to interconnected 'ball-like' particles resulting in a 3D quasi-network. Particularly, the formation of this nano-/micro texture led to a slight increase of the surface roughness, in the case of both the adopted substrates. Moreover, a negligible water absorption and a good degree of transparency also occur for either Carrara marble or glass materials, respectively. Alongside, the addition of commercial additives to Alpha and Bluesil coatings improves the final water repellency (i.e. low SFE polar component values), although without reaching the TCMS performances (contact angle up to $140^{\circ}$ ). Eventually, the stability of all the adopted coatings towards UV light (performed by accelerated ageing tests) was assessed. However, further studies will be necessary to enhance their durability, especially in the case of TCMS-clad glass material.

Thus, thanks to $i$ ) the achieved high degree of hydrophobicity features, ii) the hindering of water capillary absorption, and iii) the reduction of water permeability within the acceptable limit (\%RPV below $50 \%$ ), TCMS reveals to be a novel optimal silane-based hydrophobizing agent for both glass and marble substrates.

\section{Declaration of Competing Interest}

The authors declare that there is no conflict of interest regarding the publication of this paper.

\section{Acknowledgment}

The use of profilometer, purchased through the Regione Lombardia - Fondazione Cariplo joint SmartMatLab project (Fondazione Cariplo 2013-1766 project), is gratefully acknowledged.

\section{Appendix A. Supplementary data}

Supplementary material related to this article can be found, in the online version, at doi:https://doi.org/10.1016/j.porgcoat.2019.105260.

\section{References}

[1] M.J. Mosquera, L. Pinho, D.S. Facio, F. Elhaddad, , New nanomaterials for conser vation of cultural heritage: consolidants, hydrophobic and self-cleaning products, Heritage, 2014, Sci. Technol. Cult. Herit. - Proc. 2nd Int. Congr. Sci. Technol. Conserv. Cult (2014) 121-126.

[2] S. Eyssautier-Chuine, I. Calandra, N. Vaillant-Gaveau, G. Fronteau, C. Thomachot-Schneider, J. Hubert, J. Pleck, M. Gommeaux, A new preventive coating for building stones mixing a water repellent and an eco-friendly biocide, Prog. Org. Coatings120 (2018) 132-142, https://doi.org/10.1016/J.PORGCOAT.2018.03. 022.

[3] A. Antonello, G. Soliveri, D. Meroni, G. Cappelletti, S. Ardizzone, Photocatalytic re mediation of indoor pollution by transparent $\mathrm{TiO}_{2}$ films, Catal. Today230 (2014) https://doi.org/10.1016/j.cattod.2013.12.033.

[4] G. Soliveri, V. Pifferi, R. Annunziata, L. Rimoldi, V. Aina, G. Cerrato, L. Falciola, G. Cappelletti, D. Meroni, Alkylsilane-SiO ${ }_{2}$ Hybrids. A Concerted Picture of Temperature Effects in Vapor Phase Functionalization, J. Phys. Chem. C. 119 (2015) 15390-15400, https://doi.org/10.1021/acs.jpcc.5b04048.

[5] A.Y. Fadeev, T.J. McCarthy, Self-assembly is not the only reaction possible between alkyltrichlorosilanes and surfaces: monomolecular and oligomeric covalently attached layers of dichloro- and trichloroalkylsilanes on silicon, Langmuir16 (2000) 7268-7274, https://doi.org/10.1021/la000471z.

[6] I. Karapanagiotis, A. Pavlou, P.N. Manoudis, K.E. Aifantis, Water repellent ORMOSIL films for the protection of stone and other materials, Mater. Lett. 131 (2014) 276-279, https://doi.org/10.1016/j.matlet.2014.05.163.

[7] E. Quagliarini, F. Bondioli, G. Battista, A. Licciulli, P. Munafò, Self-cleaning materials on Architectural Heritage: Compatibility of photo-induced hydrophilicity of $\mathrm{TiO}_{2}$ coatings on stone surfaces, J. Cult. Herit. 14 (2013) 1-7, https://doi.org/10. 1016/j.culher.2012.02.006.

[8] P. Fermo, G. Cappelletti, N. Cozzi, G. Padeletti, S. Kaciulis, M. Brucale, M. Merlini, Hydrophobizing coatings for cultural heritage. A detailed study of resin/stone surface interaction, Appl. Phys. A. 116 (2014) 341-348, https://doi.org/10.1007/ s00339-013-8127-z

[9] P. Manoudis, S. Papadopoulou, I. Karapanagiotis, A. Tsakalof, I. Zuburtikudis, C. Panayiotou, Polymer-Silica nanoparticles composite films as protective coatings for stone-based monuments, J. Phys. Conf. Ser. 61 (2007) 1361-1365, https://doi.org/ 10.1088/1742-6596/61/1/269.

[10] C. Esposito Corcione, R. Striani, M. Frigione, Novel hydrophobic free-solvent UV-cured hybrid organic-inorganic methacrylic-based coatings for porous stones, Prog. Org. Coatings77 (2014) 803-812, https://doi.org/10.1016/j.porgcoat.2014. 01.008.

[11] R.J. Flatt, Salt damage in porous materials: how high supersaturations are generated, J. Cryst. Growth242 (2002) 435-454, https://doi.org/10.1016/S00220248(02)01429-X.

[12] D. Gulotta, M. Bertoldi, S. Bortolotto, P. Fermo, A. Piazzalunga, L. Toniolo, The Angera stone: a challenging conservation issue in the polluted environment of Milan (Italy), Environ. Earth Sci. 69 (2013) 1085-1094, https://doi.org/10.1007/ s12665-012-2165-2.

[13] G. Le Métayer-Levrel, S. Castanier, G. Orial, J.F. Loubière, J.P. Perthuisot, Applications of bacterial carbonatogenesis to the protection and regeneration of limestones in buildings and historic patrimony, Sediment. Geol. 126 (1999) 25-34, https:// doi.org/10.1016/S0037-0738(99)00029-9. 
[14] F. Jroundi, A. Fernández-Vivas, C. Rodriguez-Navarro, E.J. Bedmar, M.T. González-Muñoz, Bioconservation of deteriorated monumental calcarenite stone and identification of bacteria with carbonatogenic activity, Microb. Ecol. 60 (2010) 39-54, https://doi.org/10.1007/s00248-010-9665-y.

[15] C. Esposito Corcione, N. De Simone, M.L. Santarelli, M. Frigione, Protective properties and durability characteristics of experimental and commercial organic coatings for the preservation of porous stone, Prog. Org. Coatings103 (2017) 193-203, https://doi.org/10.1016/j.porgcoat.2016.10.037.

[16] B. Doherty, M. Pamplona, R. Selvaggi, C. Miliani, M. Matteini, A. Sgamellotti, B. Brunetti, Efficiency and resistance of the artificial oxalate protection treatment on marble against chemical weathering, Appl. Surf. Sci. 253 (2007) 4477-4484, https: //doi.org/10.1016/j.apsusc.2006.09.056.

[17] P. Rizzarelli, C. La Rosa, A. Torrisi, Testing a fluorinated compound as a protective material for calcarenite, J. Cult. Herit. 2 (2001) 55-62, https://doi.org/10.1016/ S1296-2074(01)01109-8.

[18] J. Zhang, S. Seeger, Silica/Silicone nanofilament hybrid coatings with almost perfect superhydrophobicity, ChemPhysChem. 14 (2013) 1646-1651, https://doi.org/ 10.1002/cphc.201200995

[19] V. Sabatini, C. Cattò, G. Cappelletti, F. Cappitelli, S. Antenucci, H. Farina, M.A. Ortenzi, S. Camazzola, G. Di Silvestro, Protective features, durability and biodegration study of acrylic and methacrylic fluorinated polymer coatings for marble protection, Prog. Org. Coatings114 (2018) https://doi.org/10.1016/j.porgcoat.2017. 10.003 .

[20] E. Carretti, L. Dei, Physicochemical characterization of acrylic polymeric resins coating porous materials of artistic interest, Prog. Org. Coatings49 (2004) 282-289, https://doi.org/10.1016/j.porgcoat.2003.10.011.

[21] M. Mazzola, P. Frediani, S. Bracci, A. Salvini, New strategies for the synthesis of partially fluorinated acrylic polymers as possible materials for the protection of stone monuments, Eur. Polym. J. 39 (2003) 1995-2003, https://doi.org/10.1016/ S0014-3057(03)00110-1.

[22] V. Sabatini, H. Farina, A. Montarsolo, E. Pargoletti, M.A. Ortenzi, G. Cappelletti, Fluorinated polyacrylic resins for the protection of cultural heritages: the effect of fluorine on hydrophobic properties and photochemical stability, Chem. Lett. 47 (2018) https://doi.org/10.1246/cl.171020.

[23] P.N. Manoudis, I. Karapanagiotis, A. Tsakalof, I. Zuburtikudis, B. Kolinkeová, C. Panayiotou, Superhydrophobic films for the protection of outdoor cultural heritag assets, Appl. Phys. A Mater. Sci. Process. 97 (2009) 351-360, https://doi.org/10. 1007/s00339-009-5233-z.

[24] M. Zielecka, E. Bujnowska, K. Bajdor, Siloxane-containing polymer matrices as coating materials, J. Coat. Technol. Res. 4 (2007) 275-281, https://doi.org/10. 1007/s11998-007-9028-x.

[25] A. Stewart, B. Schlosser, E.P. Douglas, Surface modification of cured cement pastes by silane coupling agents, ACS Appl. Mater. Interfaces5 (2013) 1218-1225, https: //doi.org/10.1021/am301967v.

[26] Q. Rao, K. Chen, C. Wang, Facile preparation of self-healing waterborne superhydrophobic coatings based on fluoroalkyl silane-loaded microcapsules, RSC Adv. 6 (2016) 53949-53954, https://doi.org/10.1039/C6RA09582H.

[27] E.G. Atici, E. Kasapgil, I. Anac, H.Y. Erbil, Methyltrichlorosilane polysiloxane filament growth on glass using low cost solvents and comparison with gas phase reactions, Thin Solid Films616 (2016) 101-110, https://doi.org/10.1016/j.tsf.2016.07. 041.

[28] I. Karapanagiotis, P.N. Manoudis, A. Savva, C. Panayiotou, Superhydrophobic polymer-particle composite films produced using various particle sizes, Surf. Interface Anal. 44 (2012) 870-875, https://doi.org/10.1002/sia.4930.

[29] A. Tsakalof, P. Manoudis, I. Karapanagiotis, I. Chryssoulakis, C. Panayiotou, Assessment of synthetic polymeric coatings for the protection and preservation of stone monuments, J. Cult. Herit. 8 (2007) 69-72, https://doi.org/10.1016/J. CULHER.2006.06.007.

[30] J.X.H. Wong, H. Asanuma, H.-Z. Yu, Simple and reproducible method of preparing transparent superhydrophobic glass, Thin Solid Films522 (2012) 159-163, https:// doi.org/10.1016/j.tsf.2012.08.033.
[31] X. Zhang, F. Shi, J. Niu, Y. Jiang, Z. Wang, Superhydrophobic surfaces: from structural control to functional application, J. Mater. Chem. 18 (2008) 621-633, https: //doi.org/10.1039/B711226B.

[32] L. Gao, T.J. McCarthy, A perfectly Hydrophobic Surface $\left(\theta_{A} / \theta_{R}=180^{\circ} / 180^{\circ}\right)$, J. Am. Chem. Soc. 128 (2006) 9052-9053, https://doi.org/10.1021/ja062943n.

[33] F. Pino, P. Fermo, M. La Russa, S. Ruffolo, V. Comite, J. Baghdachi, E. Pecchioni, F. Fratini, G. Cappelletti, Advanced mortar coatings for cultural heritage protection. Durability towards prolonged UV and outdoor exposure, Environ. Sci. Pollut. Res. 24 (2017) 12608-12617, https://doi.org/10.1007/s11356-016-7611-3.

[34] G. Cappelletti, P. Fermo, M. Camiloni, Smart hybrid coatings for natural stones conservation, Prog. Org. Coatings78 (2015) 511-516, https://doi.org/10.1016/j. porgcoat.2014.05.029.

[35] G. Cappelletti, P. Fermo, Hydrophobic and superhydrophobic coatings for limestone and marble conservation, in: M.F. Montemor (Ed.), Smart Compos. Coating Membr. Transp. Struct. Environ. Energy Appl., Elsevier, 2016, p. 490.

[36] J. Zhang, L. Li, B. Li, S. Seeger, Solvent-controlled growth of silicone nanofilaments, RSC Adv. 4 (2014) 33424, https://doi.org/10.1039/C4RA04475D.

[37] D. Meroni, S. Ardizzone, G. Cappelletti, M. Ceotto, M. Ratti, R. Annunziata, M. Benaglia, L. Raimondi, Interplay between chemistry and texture in hydrophobic $\mathrm{TiO}_{2}$ hybrids, J. Phys. Chem. C. 115 (2011) 18649-18658, https://doi.org/10. 1021/jp205142b.

[38] D.K. Owens, R.C. Wendt, Estimation of the surface free energy of polymers, J. Appl. Polym. Sci. 13 (1969) 1741-1747.

[39] G. Cappelletti, S. Ardizzone, D. Meroni, G. Soliveri, M. Ceotto, C. Biaggi, M. Benaglia, L. Raimondi, Wettability of bare and fluorinated silanes: a combined approach based on surface free energy evaluations and dipole moment calculations, J. Colloid Interface Sci. 389 (2013) 284-291, https://doi.org/10.1016/j.jcis.2012. 09.008.

[40] Conservation of Cultural Property - Test Methods - Determination of Water Absorption by Capillarity, 15801 UNI EN, 2010.

[41] G. Cappelletti, P. Fermo, F. Pino, E. Pargoletti, E. Pecchioni, F. Fratini, S.A. Ruffolo, M.F. La Russa, On the role of hydrophobic Si-based protective coatings in limiting mortar deterioration, Environ. Sci. Pollut. Res. 22 (2015) 17733-17743, https://doi.org/10.1007/s11356-015-4962-0.

[42] Conservation of Cultural Property - Test Methods - Determination of Water Vapour Permeability, 15803 UNI EN, 2009.

[43] P.N. Manoudis, A. Tsakalof, I. Karapanagiotis, I. Zuburtikudis, C. Panayiotou, Fabrication of super-hydrophobic surfaces for enhanced stone protection, Surf. Coatings Technol. 203 (2009) 1322-1328, https://doi.org/10.1016/j.surfcoat.2008.10. 041.

[44] M.F. La Russa, S.A. Ruffolo, N. Rovella, C.M. Belfiore, A.M. Palermo, M.T. Guzzi, G.M. Crisci, Multifunctional $\mathrm{TiO}_{2}$ coatings for cultural heritage, Prog. Org. Coatings 74 (2012) 186-191, https://doi.org/10.1016/j.porgcoat.2011.12.008.

[45] H.S. Khoo, F.G. Tseng, Engineering the 3D architecture and hydrophobicity of methyltrichlorosilane nanostructures, Nanotechnology19 (2008), 345603https:// doi.org/10.1088/0957-4484/19/34/345603.

[46] L. Wang, J. Wei, Z. Su, Fabrication of surfaces with extremely high contact angle hysteresis from polyelectrolyte multilayer, Langmuir 27 (2011) 15299-15304, https://doi.org/10.1021/la2039448.

[47] J. Zimmermann, F.A. Reifler, U. Schrade, G.R.J. Artus, S. Seeger, Long term environmental durability of a superhydrophobic silicone nanofilament coating, Colloids Surfaces A Physicochem. Eng. Asp. 302 (2007) 234-240, https://doi.org/10.1016/ j.colsurfa.2007.02.033.

[48] C. Kapridaki, P. Maravelaki-Kalaitzaki, $\mathrm{TiO}_{2}-\mathrm{SiO}_{2}-\mathrm{PDMS}$ nano-composite hydrophobic coating with self-cleaning properties for marble protection, Prog. Org. Coatings76 (2013) 400-410, https://doi.org/10.1016/j.porgcoat.2012.10.006.

[49] J.D. Rodrigues, A. Grossi, Indicators and ratings for the compatibility assessment of conservation actions, J. Cult. Herit. 8 (2007) 32-43, https://doi.org/10.1016/j culher.2006.04.007. 